\title{
Study of the interaction of 5-(alkylthio)-3H-1,2-dithiole-3-thiones with $\beta$-cyclodextrin
}

\author{
Martín E. Zoloff Michoff, Alejandro M. Granados, and Rita H. de Rossi* \\ Instituto de Investigaciones en Físico-Química de Córdoba (INFIQC), Departamento de \\ Química Orgánica, Facultad de Ciencias Químicas, Universidad Nacional de Córdoba. Ciudad \\ Universitaria 5000 Córdoba, Argentina \\ E-mail: ritah@dqo.fcq.unc.edu.ar
}

\section{In honor of Professor Rosa M. de Lederkremer in occasion of her $\mathbf{7 0}^{\text {th }}$ birthday}

\begin{abstract}
Dithiolthiones are a family of compounds which have a great current interest for their properties especially as anti carcinogens. The problem for the use of this type of compounds is that they are quite water insoluble and this represents a problem for their bioavalability. We have studied the interaction of 5-RS-3H-1,2-dithiole-3-thiones $(\mathrm{R}=$ ethyl, butyl, hexyl and octyl) with cyclodextrins and we report here that the ethyl and butyl derivatives form inclusion complexes with $\beta$-cyclodextrin with 1:1 stoichiometry. The complexes are characterized by Uv-vis, circular dichroism spectroscopy and by DSC analysis of the solid complexes. The solubility of the butyl derivative in water increases about two times in a solution of $\beta$-cyclodextrin $0.01 \mathrm{M}$. The hexyl and octyl derivatives are aggregated in water even at $4-5 \times 10^{-6} \mathrm{M}$ and in the presence of $0.001 \mathrm{M}$ $\beta$-CD they are associated with destruction of the aggregates. The spectroscopic behavior indicates that these derivatives form complexes of higher stoichiometry probably 1:2.
\end{abstract}

Keywords: Thione, cyclodextrin, association equilibrium

\section{Introduction}

The heterocyclic pseudoaromatic compounds $3 H$-1,2-dithiole-3-thiones 1 have been known for several years. ${ }^{1}$

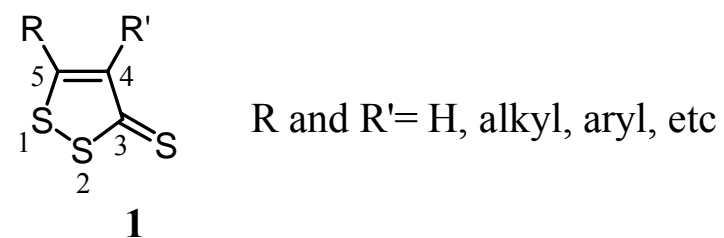


A wide variety of alkyl and aryl derivatives have been synthesized and a great number of these compounds display biological activity and industrial applications. For instance, Oltipraz (4methyl-5-pyrazinyl-3H-1,2-dithiole-3-thione) was originally used as an antischistosomal agent due to its remarkable activity against Schistosoma mansoni. ${ }^{2}$ In addition, studies have demonstrated that Oltipraz inhibits HIV-1 (AIDS) ${ }^{3}$ virus replication by irreversibly binding to the viral reverse transcriptase enzyme. This compound has also shown chemoprotective activity against a great variety of carcinogens and investigations are in progress to determine its probable use as a chemoprotective agent. ${ }^{4}$

Other derivatives like 4-aryl-5-chloro-3H-1,2-dithiole-3-thiones have been found to be fungitoxic ${ }^{5}$ and they have also been used as insecticides. ${ }^{6}$

We reported that several derivatives have interesting activity as antimicotic agent. ${ }^{7}$ One drawback of these compounds is their very low water solubility. It is very well known that ciclodextrins are useful in formulating several compounds because they form complexes which increase the solubility and/or bioavailability of the pharmaceutical compound. ${ }^{8}$ Therefore we have undertaken this study of the interaction of $3 H$-1,2-dithiole-3-thiones 2 with $\beta$-cyclodextrin. All the thiones interact with the host and form complexes that could be characterized in the solid as well as in solution and the results are reported here.

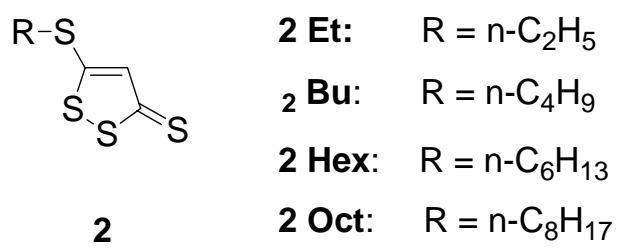

\section{Results and Discussion}

The UV-vis absorption spectra of 3H-1,2-dithiole-3-thiones 2Et and $\mathbf{2 B u}$ show two bands, one centered at $330 \mathrm{~nm}$ and other at about $400 \mathrm{~nm}$ and the ratio between the absortivity coefficients of the two bands is about one in water solution. On the other hand in non-polar solvents such as isooctane the long wavelength absorption band shifts to $421 \mathrm{~nm}$ and the ratio of the absorptivity coefficients of the low and high wavelength bands changes to aproximately 0.5 . (Figure 1 is representative). 


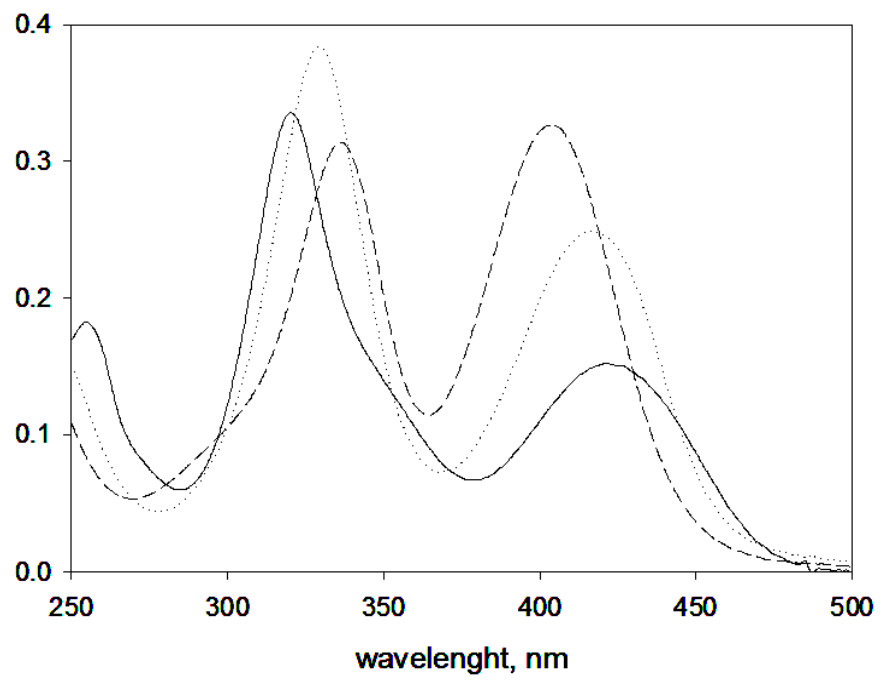

Figure 1. Spectra of $\mathbf{2 B u}$ in different solvents. Water with $5 \%$ acetonitrile ----, acetonitrile ----, isooctane ---. Temperature $25^{\circ} \mathrm{C},[2 \mathbf{B u}]_{\mathrm{o}}=2 \times 10^{-5} \mathrm{M}$.

The addition of $\beta$-cyclodextrin to a water solution of $\mathbf{2 E t}$ or $\mathbf{2 B u}$ produces a bathochromic shift, a decrease in the absorptivity coefficient of the longer wavelength absorption band and a decrease in the absorption ratio of the peaks at $\sim 350$ and $\sim 400 \mathrm{~nm}$. Besides in solutions containing different amount of cyclodextrin a well defined isosbestic point is observed. (Figure 2 is representative)

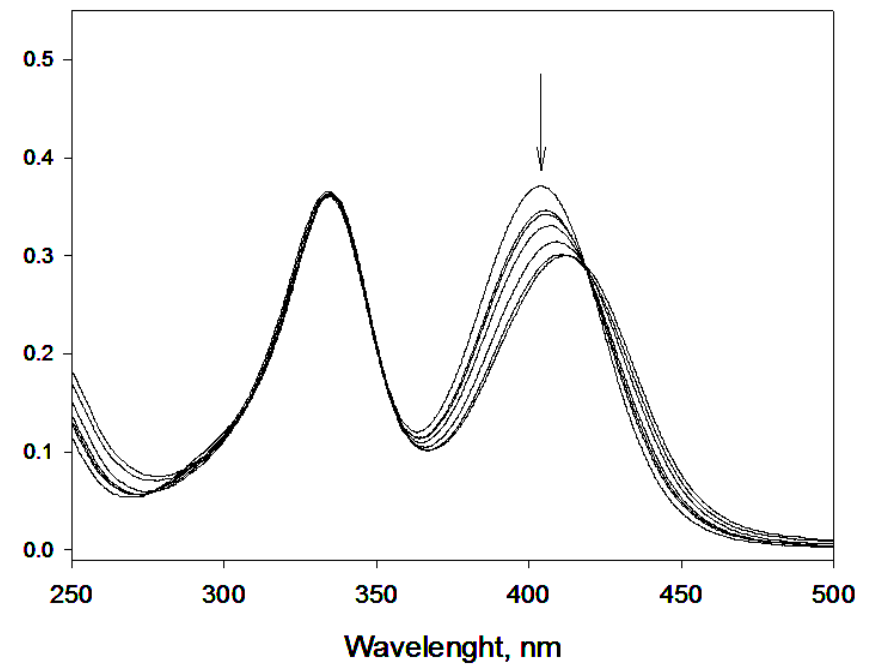

Figure 2. Spectrum of $2 \mathrm{Et}\left(3 \times 10^{-5} \mathrm{M}\right)$ at variable concentration of $\beta$-cyclodextrin $(\beta-\mathrm{CD})$. The concentration of $\beta-\mathrm{CD}$ increases in the sense indicated by the arrow from 0 to $10^{-2} \mathrm{M}$.

The spectroscopic behavior of these substrates is consistent with the formation of an inclusion complex between the thione and the cyclodextrin since it is known that the cavity of $\beta$ - 
cyclodextrin is less polar than water ${ }^{9}$ and the changes of the spectrum in the presence of cyclodextrin are similar to those found when the solvent is changed from water to a non polar solvent.

We suggest that a 1:1 inclusion complex is formed as indicated in eq 1 where $\mathrm{T}$ represents the thione and $\mathrm{CD}$ the cyclodextrin

$$
\mathbf{T}+\mathbf{C D} \stackrel{\mathrm{K}_{1}}{\rightleftharpoons} \mathrm{TCD}
$$

The change in absorbance at a given wavelength for the equilibrium shown in eq 1 is given by eq 2

$$
A-A_{o}=\frac{\Delta \varepsilon K_{1}[T]_{o}[C D]_{o}}{1+K_{1}[C D]_{o}}
$$

Where $\Delta \varepsilon$ is the difference in extinction coefficients of the free and complexed thione. Nonlinear fitting of the observed absorption at a given wavelength and different concentration of cyclodextrin gives $\mathrm{K}_{1}$ and the calculated absorption match the observed values (Figure $3 \mathrm{~A}$ ). Alternatively, equation 2 can be rearranged to eq 3

$$
\frac{1}{A-A_{o}}=\frac{1}{\Delta \varepsilon K_{1}[T]_{o}[C D]_{o}}+\frac{1}{\Delta \varepsilon[T]_{o}}
$$

A plot of $1 /\left(A-A_{o}\right)$ vs $1 /[C D]_{\mathrm{o}}$ is linear and from the ratio of the slope and the intercept the value of $K_{1}$ can be calculated (Figure $3 \mathrm{~B}$ ). The values calculated by both methods are the same within experimental error which is a good indication that the complex is formed according to eq 1. Besides the $\mathrm{K}$ obtained are the same at the two measured wavelength confirming the 1:1 stoichiometry of the complex. Similar results were obtained for $\mathbf{2 E t}$ and $\mathbf{2 B u}$ and the data are summarized in Table 1. 

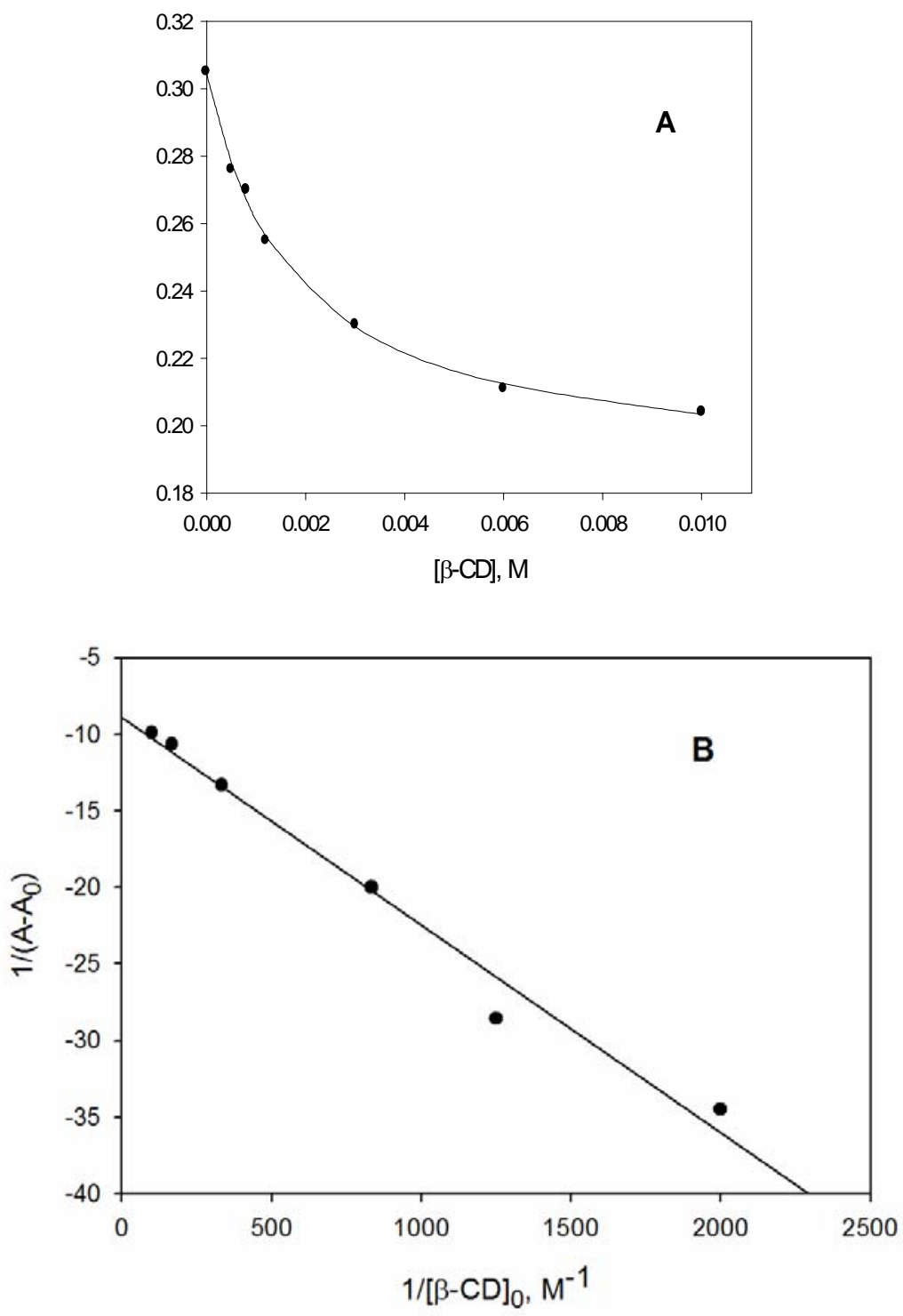

Figure 3. (A)Absorbance of a solution of 2Et as a function of $\beta$-cyclodextrin concentration, the line represents the fit using eq 2. (B) Plot of the data according to eq 3.

Cyclodextrins are cyclic oligomers of $\alpha$-D-glucose and they have truncated cone shape where the secondary $\mathrm{OH}$ are at the wider rim of the cone and the primary $\mathrm{OH}$ are located at the smaller rim of the cavity. The size of the cavity depends on the number of glucose units and are summarized in Table 2. It is known that there are several forces that contribute to the interaction between a host and a guest, hydrophobic, dipole-dipole, electrostatic, hydrogen bonding, etc. ${ }^{10}$ Substrates 2 are highly hydrophobic ${ }^{11,12}$ so it is possible that the major interaction is of this type.

The interaction of $\mathbf{2 B u}$ with $\alpha$ and $\gamma$ ciclodextrins gives rise to similar spectral changes as those observed using $\beta$-cyclodextrin (Figure 4). 


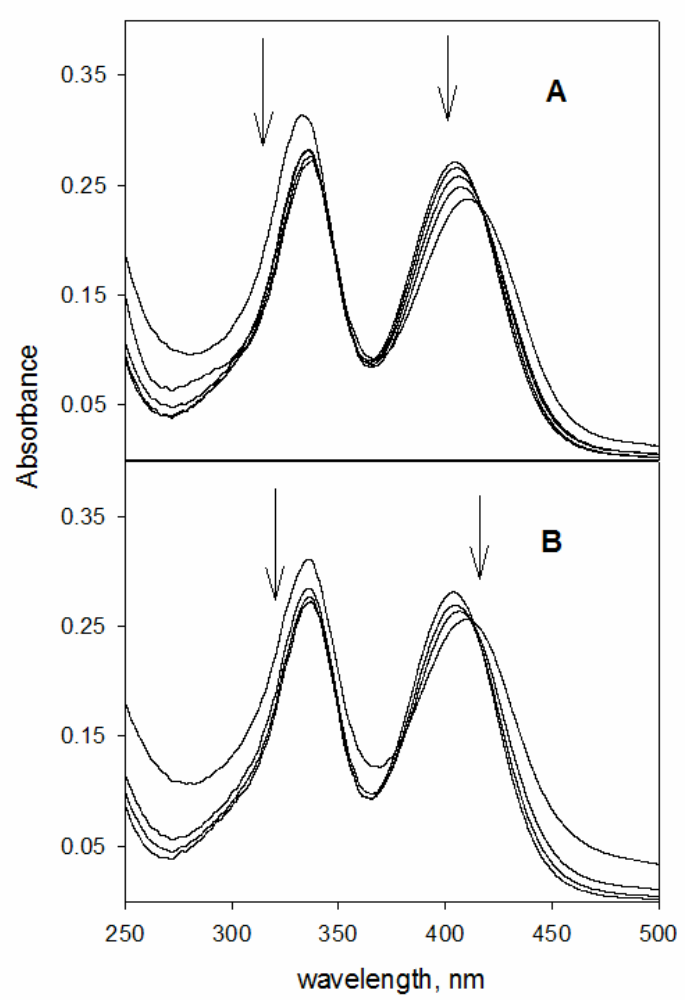

Figure 4. Spectra of $\mathbf{2 B u}$ with different cyclodextrin concentration. (A) $\alpha$-cyclodextrin at concentration $0-2.4 \times 10^{-2} \mathrm{M}(\mathrm{B}) \gamma$-cyclodextrin $0-2.0 \times 10^{-2} \mathrm{M}$ from top to bottom. $[2 \mathbf{B u}]_{\mathrm{o}}=1.8 \times 10^{-}$ ${ }^{5} \mathrm{M}$. Solvent: water and $4 \% \mathrm{v} / \mathrm{v}$ acetonitrile.

The changes in absorbance at the two wavelengths shown in Table 1 follow eq 2 and 3 however significant differences are observed for the values of the equilibrium constant calculated using the data at the two wavelengths (see Table 1). This differences can be attributed to the formation of complexes of different stoichiometry. ${ }^{13}$

Table 1. Equilibrium constants for the association of thiones 2 with cyclodextrins ${ }^{\mathrm{a}}$

\begin{tabular}{ccc}
\hline Substrate(cyclodextrin) & \multicolumn{2}{c}{$\mathrm{K}, \mathrm{M}^{-1}$} \\
\hline $\mathbf{2 E t}(\beta)$ & $\lambda=390 \mathrm{~nm}$ & $\lambda=430 \mathrm{~nm}$ \\
$\mathbf{2 B u}(\beta)$ & $1057 \pm 120$ & $472 \pm 32$ \\
$\mathbf{2 B u}(\alpha)$ & $191 \pm 35$ & $911 \pm 114$ \\
$\mathbf{2 B u}(\gamma)$ & $226 \pm 27$ & $105 \pm 29$ \\
\hline
\end{tabular}

${ }^{\text {a }}$ Temperature $25^{\circ} \mathrm{C}$, Solvent: water with $4 \%$ CAN. 
Table 2. Dimensions in Angstroms of the cyclodextrins cavity ${ }^{\mathrm{a}}$

\begin{tabular}{ccc}
\hline Cyclodextrin & $\begin{array}{c}\text { Small diameter } \\
\text { (measured at } \mathrm{C}(6))\end{array}$ & $\begin{array}{c}\text { Large diameter } \\
\text { (measured at } \mathrm{O}(2))\end{array}$ \\
\hline$\alpha$ & 5.6 & 8.8 \\
$\beta$ & 6.8 & 10.8 \\
$\gamma$ & 8.0 & 12.8 \\
\hline
\end{tabular}

${ }^{\text {a }}$ Data taken from reference 14 , the height of the cavity is $7.8 \AA$ for all of them.

The existence of an inclusion complex can be proved by the comparison of thermoanalytical curves of the pure cyclodextrin, the pure guest, their mechanical mixture and the putative inclusion complex. ${ }^{15}$ The data from the DSC of $\mathbf{2 B u}, \beta$-cyclodextrin, the mechanical 1:1 mixture and the complex prepared by freeze drying of a 1:1 solution of $\mathbf{2 B u}$ and $\beta-C D$ are shown in Table 3. The data clearly show the differences between the thermochemical data of the four type of samples which is a good indication that a complex between cyclodextrin and $\mathbf{2 B u}$ is formed. Some particular features are worth to note: i) the first endothermic peak of $\mathbf{2} \mathbf{B u}$ correspond to its melting point. In the complex this peak appears 1.85 degrees bellow and in the mechanical mixture 1.07 degree above this value. These results are common in other compounds and have been attributed to changes in the stability of the substrate when it is complexed; ${ }^{16}$ ii) the main differences between the mechanical mixtures and the complex are that the well defined endothermic peaks observed with pure cyclodextrin and in the mixture are replaced in the complex by a broad peak with minima at the temperatures indicated in Table 3 . Besides, there is a strong exothermic peak which in the complex appears with stronger heat flow and at 13 and 11 degrees above the value observed for cyclodextrin and the mechanical mixture respectively.

Table 3. DSC data for $\mathbf{2 B u}, \beta-C D$, a 1:1 mechanical mixture of the two compounds and the complex. The numbers are the temperature in centigrade degrees and correspond to endothermic transitions unless otherwise noticed

\begin{tabular}{cccc}
\hline 2-Bu & $\beta-C D$ & Complex & $1: 1$ mechanical mixture \\
\hline 47.85 & & 46.00 & 48.92 \\
223.49 & 130.21 & $138.86^{\mathrm{a}}$ & 140.40 \\
& & $171.50^{\mathrm{a}}$ & \\
& & $249.40^{\mathrm{a}}$ & 271.23 \\
& $316.54^{\mathrm{b}}$ & $329.31^{\mathrm{b}}$ & $318.10^{\mathrm{b}}$ \\
\hline
\end{tabular}

${ }^{\mathrm{a}}$ Broad peak. ${ }^{\mathrm{b}}$ Exothermic transitions.

The induced circular dichroism spectrum (Figure 5) observed when cyclodextrins are added to an aqueous solution of $\mathbf{2} \mathbf{B u}$ confirms the formation of a complex. The sign of the bands observed are positive in the whole range of the Uv-vis spectrum, although the relative magnitude 
of the elipticity of the bands varies for $\alpha-\beta$ - and $\gamma$ ciclodextrins. According to theoretical studies ${ }^{17,18}$ the sign of circular dichroism exhibited by a molecule incorporated in a cyclodextrin cavity is determined by the angle between the transition moment vector of a molecule chromophore and the sixth, seventh or eight fold symmetry axes of $\alpha$ - $\beta$ - and $\gamma$-cyclodextrin respectively. If the transition moment is perpendicular to the symmetry axis of the cyclodextrin ring, the sign of the induced circular dichroism is negative and if the transition moment is parallel to the axis, the sign is positive. The $S_{0} \rightarrow S_{2}$ transition moment in thiolketones is parallel to the $\mathrm{C}-\mathrm{S}$ bond ${ }^{19}$ therefore the sign of the circular dichroism suggests that the C-S bond of the complexed molecule is parallel to the symmetry axis of the host molecule. A possible structure of the complex is shown in Figure 6.

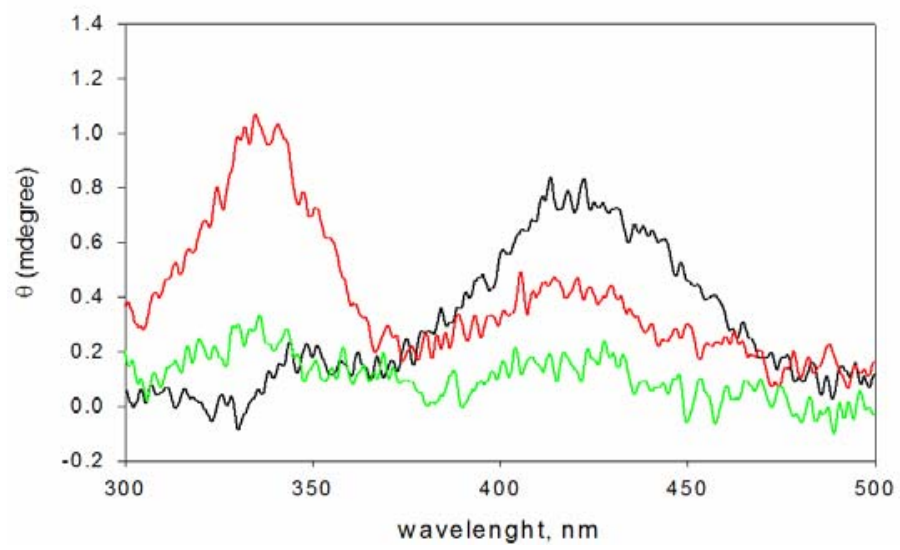

Figure 5. Circular dichroism spectra of $\mathbf{2 B u}\left(2 \times 10^{-5} \mathrm{M}\right)$ in the presence of different cyclodextrins. Solvent: water with $4 \%$ acetonitrile, Temperature $25{ }^{\circ} \mathrm{C}[\alpha-\mathrm{CD}]=0.03 \mathrm{M}-$ $[\beta-\mathrm{CD}]=0.01 \mathrm{M} \longrightarrow[\gamma-\mathrm{CD}]=0.02 \mathrm{M} \longrightarrow$.

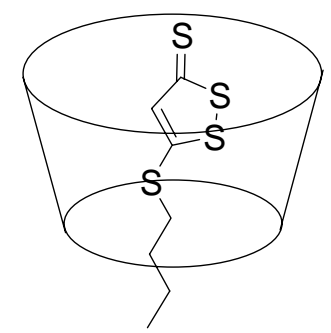

Figure 6. Schematic representation of the structure of the complex between $\mathbf{2 B u}$ and $\beta$ cyclodextrin.

The spectroscopic behavior of 2Hex and 20ct is different from those of the shorter chain compounds. For both compounds the spectrum in water solution shows a broad absorption above $450 \mathrm{~nm}$ and the extinction coefficient at the absorption maxima are lower than those for the other thiones. Besides the long wavelength maximum is located at 407 and $445 \mathrm{~nm}$ and the minimum 
at 368 and 385 for the $\mathbf{2 H e x}$ and 2Oct derivatives respectively (see Figures 7 and 8 ). The ratio of absorption between the maximum and the valley are 1.72 and 1.67 for the $\mathbf{2 H e x}$ and 2Oct derivatives respectively. On the other hand, for the $\mathbf{2 E t}$ derivative the ratio of absorption of the band at $404 \mathrm{~nm}$ and the minimum at $363 \mathrm{~nm}$ is 3.09 , i.e about twice the value for $2 \mathbf{H e x}$ and 2Oct. Besides the shape of the spectrum changes with the concentration as shown in Figure 9. It is worth to notice that the maximum absortion for $2 \mathrm{Hex}$ and 2Oct shows a bathochromic shift of 3 and $42 \mathrm{~nm}$ compared to that of $\mathbf{2 E t}$ and this may indicate that the compound is in a less polar microenvironment as expected if it is aggregated.

In the solutions with cyclodextrin also there are important differences. The addition of $1 \times 10^{-3}$ $\mathrm{M}$ of $\beta$-cyclodextrin to a solution of $\mathbf{2 H e x}$ changes the shape of the spectrum to one very similar to the spectrum of $\mathbf{2 E t}$ and $\mathbf{2 B u}$. Further addition of ciclodextrin changes the maximum absorption of the band at $408 \mathrm{~nm}$ toward longer wavelength and increase the intensity of the band at $334 \mathrm{~nm}$ (Figure 7). This behavior is quite different from that observed with 2 Et and 2 Bu (compare Figures 7 and 2)

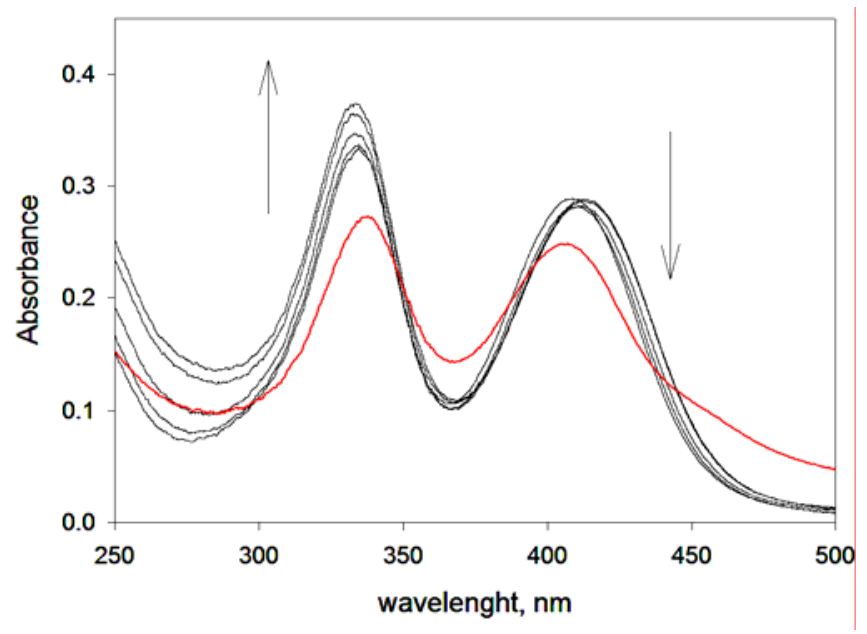

Figure 7. Spectra of $2 \mathrm{Hex}$ as a function of $\beta$-cyclodextrin concentration. $[2 \mathbf{H e x}]_{\mathrm{o}}=5 \times 10^{-6} \mathrm{M}$ (cell with $5 \mathrm{~cm}$ path length). $\beta$-Cyclodextrin concentration changes from 1 to $10 \times 10^{-3} \mathrm{M}$ as indicated by the arrows. The spectrum in red corresponds to the solution without cyclodextrin. 


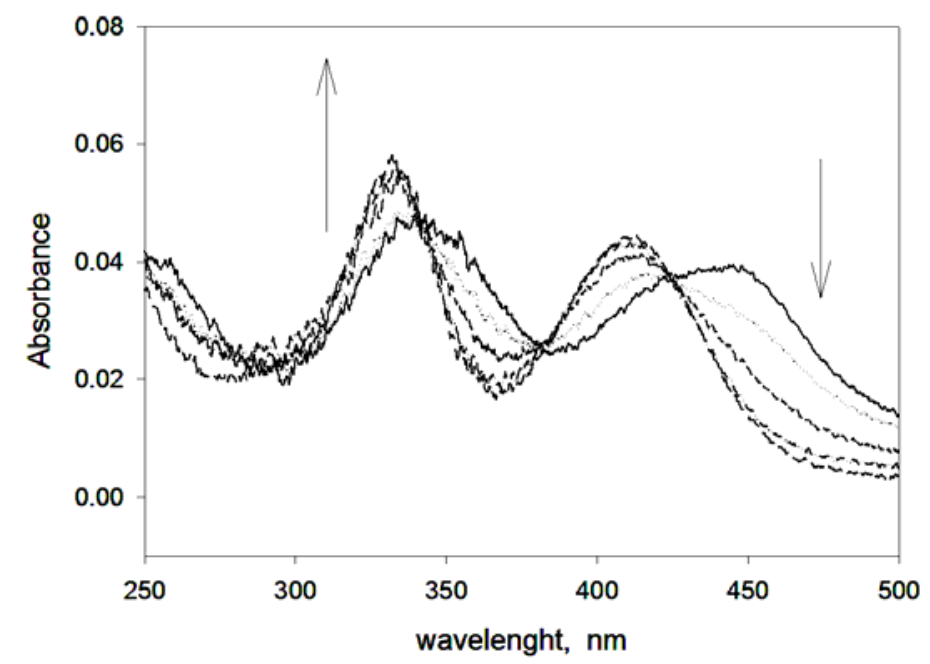

Figure 8. Spectra of 2Oct as a function of $\beta$-cyclodextrin concentration. $[2 \mathrm{Oct}]_{0}=4 \times 10^{-6} \mathrm{M} \beta$ cyclodextrin concentration changes from $0-5 \times 10^{-3} \mathrm{M}$ as indicated by the arrows. Cell path length $1 \mathrm{~cm}$.

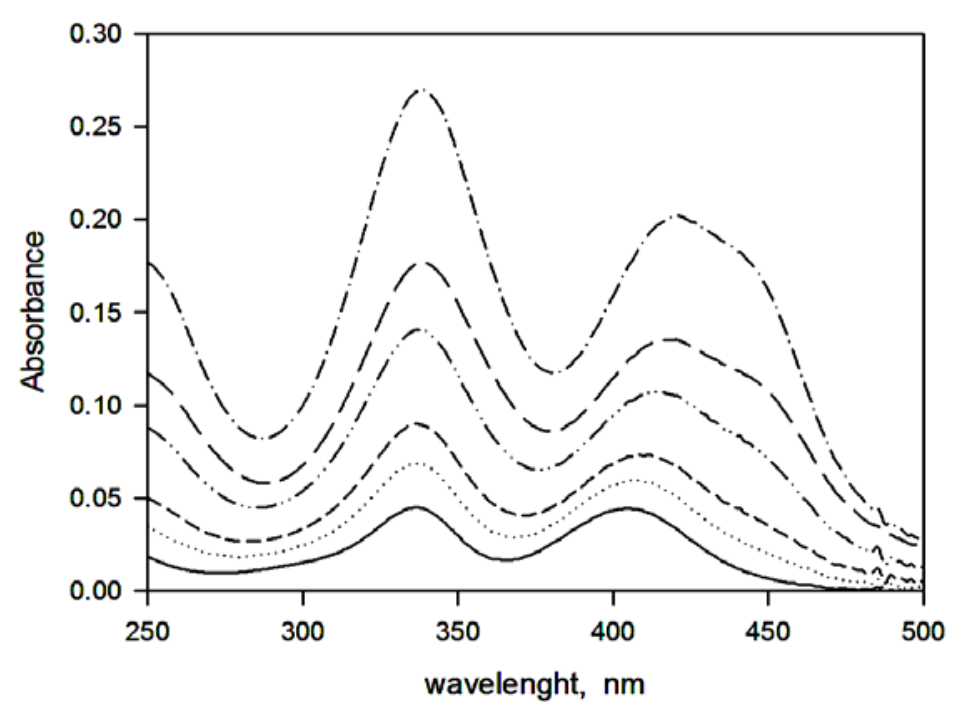

Figure 9. Spectrum of $\mathbf{2 H e x}$ in water at several concentrations: $3.36 \longrightarrow ; 5.37 \cdots \cdots . .$. 6.72 -----; 10.1 -.....-; $13.4-\left[; 20.2-\cdots \cdots 10^{-6} \mathrm{M}\right.$.

For the 2Oct derivative the maximum absorptions appear at 340 and $445 \mathrm{~nm}$. The addition of $\beta$-cyclodextrin changes them to 332 an $413 \mathrm{~nm}$ respectively with quite well defined isosbestic points at 423, 381 and $341 \mathrm{~nm}$ (Figure 8).

We suggest that $\mathbf{2 H e x}$ and $2 \mathrm{Oct}$ are aggregated in water solution, eq 4, and for $\mathbf{2 H e x}$ the first addition of cyclodextrin drives the equilibrium towards the left due to the formation of the 1:1 
inclusion complex, eq 5, further addition of cyclodextrin forms a complex of higher stoichiometry probably 1:2 complex, eq. 6

$$
\begin{aligned}
& \mathrm{nT} \stackrel{\mathrm{K}_{\text {agg }}}{\rightleftharpoons} \mathrm{T}_{\mathrm{n}} \\
& \mathrm{T}+\mathrm{CD} \stackrel{\mathrm{K}_{1}}{\rightleftharpoons} \mathrm{TCD} \\
& \mathrm{TCD}+\mathrm{CD} \stackrel{\mathrm{K}_{2}}{\rightleftharpoons} \mathrm{T}(\mathrm{CD})_{2}
\end{aligned}
$$

Using the value of the absorbance of solutions of 2 Hex containing cyclodextrin $0.001 \mathrm{M}$ as $\mathrm{A}_{\mathrm{o}}$ in eq. 3, a good linear plot is obtained (Plot not shown) and from the slope a value of $K_{a p p}$ can be obtained which is defined in eq. 7. This equation can be combined with the expression of the equilibrium constants for reactions 4-6 shown in eq. 8-10 to give eq 11

$$
\begin{aligned}
& K_{a p p}=\frac{T(C D)_{2}}{(C D)\left(T C D+T+n T_{n}\right)} \\
& K_{a g g}=\frac{T_{n}}{T^{n}} \\
& K_{1}=\frac{(T C D)}{(C D)(T)} \\
& K_{2}=\frac{\left(T C D_{2}\right)}{(T C D)(C D)} \\
& K_{a p p}=\frac{K_{2} K_{1}(C D)}{\left[K_{1}(C D)+1+n K_{a g g} T^{n-1}\right]}
\end{aligned}
$$

If we assume that $20 \%$ of the substrate is aggregated at the concentration used, $\left(5 \times 10^{-6} \mathrm{M}\right)$ we can estimate for $\mathrm{n}=2$ that $K_{\text {agg }}$ is in the order of $10^{4} \mathrm{M}$ then the term $K_{\text {agg }} T^{\mathrm{n}-1}$ in eq. 11 can be neglected. Besides, using the values of $K_{l}$ for 2Et and 2Bu (Table 1) and knowing that usually there is a linear relationship between association equilibrium constant and number of atoms in the chain, ${ }^{20}$ we can estimate that $K_{1}$ for $\mathbf{2 H e x}$ is approximately 1600 , then $K_{\text {app }} \approx K_{2}=115 \pm 32$ $\mathrm{M}^{-1}$. 
For 2Oct the spectrum (Figure 8) shows that it is highly aggregated and the fact that isosbestic points are observed probably indicate that under the conditions of the study only reactions 4 and 5 take place. A plot according to eq 3 is linear and from the slope a value of $K_{a p p}$ $=370 \mathrm{M}^{-1}$ was calculated. In this case the $K_{\text {app }}$ is given by eq 12 where $\mathrm{T}$ was simplified considering that its concentration must be smaller that that of the aggregated compound.

$$
K_{a p p}=\frac{(T C D)}{(C D)\left(T+n T_{n}\right)}=\frac{K_{1}(T)}{\left(T+n T_{n}\right)}=\frac{K_{1}(T)}{n T_{n}}
$$

The spectra of 2Oct at different CD concentrations were deconvoluted by curve fitting using three Gaussians ${ }^{21}$ and very good fit to the observed spectra was obtained with curves centered at $331 \mathrm{~nm}, 404 \mathrm{~nm}$ and the third which is centered at $426 \mathrm{~nm}$ for the solution with the lowest concentration of cyclodextrin. The longest waveleght maximum moves to longer wavelengths as cyclodextrin increases up to $4 \times 10^{-3} \mathrm{M}$ and then a small shift to $428 \mathrm{~nm}$ at $5 \times 10^{-3} \mathrm{M}$ cyclodextrin concentration (Figure 10). We think that this behavior is consistent with the formation of aggregates which are destroyed by the interaction of the thione with the cyclodextrin and then, at the highest concentration, a higher order complex is probably formed.

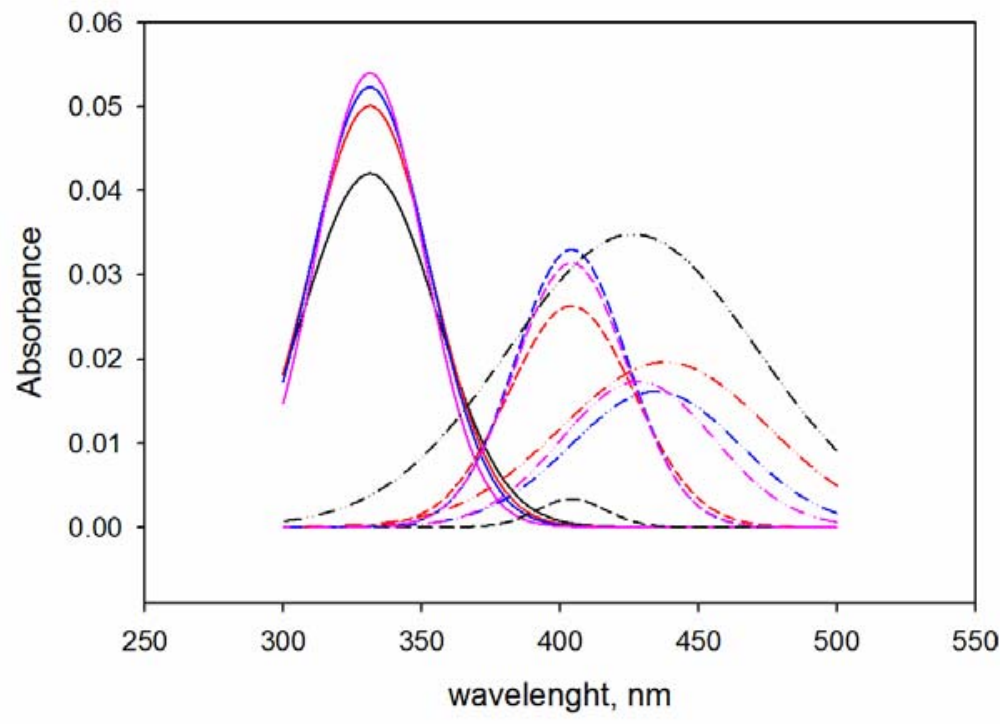

Figure 10. Deconvolution of the spectrum of 2-Oct into three Gaussians. - (1); ------ (2); $-\because--(3)$ at different cyclodextrin concentrations $(M)$ : black $(C D=0.001)$, red $(C D=0.002)$ blue $(\mathrm{CD}=0.004)$, pink $(\mathrm{CD}=0.005)$.

\section{Effect of $\beta$-cyclodextrin on the solubility}

The thiones are very hydrophobic compounds ${ }^{11}$ and so very insoluble in water which is a problem in their possible application as biologically active compounds. Cyclodextrins are 
frequently used to increase the solubility of pharmaceutical compounds. We studied the effect of $\beta$-cyclodextrin on the solubility of $\mathbf{2 B u}$. It was found that $\mathbf{2 B u}$ is about twice as soluble in $0.01 \mathrm{M}$ $\beta$-cyclodextrin than in pure water. The data are collected in Table 4.

Table 4. Solubility of $\mathbf{2 B u}$ in water and in water containing $0.01 \mathrm{M} \beta$-cyclodextrin

\begin{tabular}{cccc}
\hline \multicolumn{2}{c}{$0.01 \mathrm{M} \beta$-Cyclodextrin } & \multicolumn{2}{c}{ Water } \\
\hline Time, min & $10^{-7}$ Mole/1 & Time, min & Mole/1 \\
35 & & & \\
80 & 3.53 & 48 & 2.35 \\
130 & 4.63 & 91 & 2.46 \\
177 & 4.95 & 291 & 2.46 \\
\hline
\end{tabular}

\section{Experimental Section}

General Procedures. The $\alpha$ - and $\gamma$-cyclodextrins were obtained from Aldrich and from $\beta$ cyclodextrin Roquete $^{22}$ and they were used without further purification. Aqueous solutions were made up from water purified in a Millipore apparatus. Acetonitrile HPLC grade was used as received. The thiones 2 were prepared as described previously. ${ }^{23} \mathrm{UV}$-vis absorption spectra were done in the thermostated cell of a Shimadzu UV-PC 2100 spectrophotometer. DSC analyses were carried out in a DSC 2920 Modulated DSC Universal V2.5H TA. Circular Dichroism spectra were recorded in a Jasco spectropolarimeter.

For the determination of the association constant, a stock solution of the thione was prepared in $4 \%$ acetonitrile-water solvent, then the desired amount of cyclodextrin was weighted in a volumetric flask and the solution of the thione was added up to the mark.

Solid complex of $\mathbf{2 B u}$ and $\beta$-cyclodextrin was prepared dissolving $0.2 \mathrm{mmol}$ of cyclodextrin and $0.2 \mathrm{mmol}$ of the substrate in water and then freeze-drying the solution. To determine the solubility, an excess amount of the substrate was placed in four separated tubes, to two of them water was added and to the other a $0.01 \mathrm{M}$ cyclodextrin solution was added and they were agitated at $25^{\circ} \mathrm{C}$. At different times samples of the solution were withdrawn and the absorption was measured. The concentration was calculated using the molar extinction coefficient of $\mathbf{2 B u}$ in water which is $14600 \mathrm{M}^{-1} \mathrm{~cm}^{-1}$.

\section{Acknowledgements}

This research was supported in part by the Consejo Nacional de Investigaciones Científicas y Técnicas (CONICET), the Agencia Córdoba Ciencia, Fundación Antorchas, Agencia Nacional de Promoción Científica y Técnica (FONCYT) and the Universidad Nacional de Córdoba, Argentina 


\section{References and Footnotes}

1. (a) Landis, P. S. Chem. Rev. 1965, 65, 237. (b) Pedersen, C. Th. Adv. Heterocyclic Chem. 1982, 31, 63; Sulfur Rep. 1995, 16, 173. (c) Breslow, D. S.; Skolnik. The Chemistry of Heterocyclic Compounds, Multi Sulfur and Sulfur and Oxygen Five- and Six Membered Heterocyclic; Weissberger, A. Ed.; Wiley: New York; 1966; Part One, p 347.

2. (a) Barreau, M.; Cotrel, C.; Jeanmart, C. Ger. Offen. Patent 2,627,211; Chem. Abst. 1977, 86, 121373. (b) Barreau, M.; Cotrel, C.; Jeanmart, C. Ger. Offen. Patent 2,705,641; Chem. Abst. 1977, 87, 152171.

3. (a) Prochska, H. J.; Yeh, Y.; Baron, P.; Polsky, B. Proc. Natl. Acad. Sci. U.S.A 1993, 90, 3953. (b) Prochaska, H. J.; Rubinson, L.; Yeh, Y; Baron, P. and Polsky, B.; Molecular Pharmacology 1991, 45, 916. (c) Prochska, H. J.; Fernandes, C. L.; Pantoja, R. M.; Chavan, S. J. Biochem. Biophys. Res. Comm. 1996, 221, 548.

4. (a) Kensler, T. W.; Groopman, J. D.; Eaton, D. L.; Curphey, T. J.; Roebuck, B. D. Carcinogenesis 1992, 13, 95. (b) Prestera, T.; Talalay, P. Proc. Natl. Acad. Sci. USA 1995, 92, 8965. (c) Begleiter, A.; Leith, M. K.; Curphey, T. J. Brit. J. Cancer 1996, 74, S9-S14. (d) Begleiter, A.; Leith, M. K.; Curphey, T. J.; Doherty, G. P. Oncology Res. 1997, 9, 371. (e) Kim, W.; Gates, K. S. Chem. Res. Toxicol. 1997, 10, 296. (f) Doherty, G. P.; Leith, M. K.; Wang, X.; Curphey, T. J.; Begleiter, A. Brit. J. Cancer 1998, 77, 1241. (g) Munday, R.; Munday C. M. Carcinogenesis 2004, 25, 1721.

5. (a) Hagen, H.; Fleig, H. Ger. Offen. Patent 2,460,783; Chem. Abstr. 1976, 85, 123899. (b) Bader, J.; Gaetzi, K. Ger. Offen. Patent 1,278,701; Chem. Abstr. 1969, 70, 115147.

6. Misra, P.; Misra, S.; Mohapatra, R.; Mittra, A. J. Indian Chem. Soc. 1979, 61, 404.

7. Giannini, F. A; Aimar, M. L.; Sortino, M.; Gomez, R.; Sturniollo, A.; Juarez, A.; Zacchino, S.; de Rossi, R. H.; Enriz, R. D Il Farmaco 2004, 59, 245.

8. Uekama, K.; Hirayama, F.; Irie, T. Chem. Rev. 1998, 98, 2045.

9. (a) Connors, K. A. Chem Rev. 1997, 97, 1325. (b) ElKemary, M. A.; ElGezawy, H. S.; ElBaradie, H. Y.; Issa, R. M. Spectrochim Acta Pt A Mol. Biol. 2002, 58 (3), 493.

10. Rekharsky, M. V. Chem. Rev. 1998, 98, 1875.

11. The $\log \mathrm{P}$ value calculated by the software included in Chemdraw is 3.75 and the value calculated is usually underestimated for this type of compounds. See Ref 12.

12. Chollet Krugler, M. N.; Legouin, B.; Gargadennec, S.; Burgot, G.; Burgot, J. L. Thermochim.Acta 2004, 424, 143.

13. The stoichiometry of the complexes could in principle be determined using the method of continuous variation (Job plot) (See K.A. Connors In "Binding Constants. The Measurement of Molecular Complex Stability”, Wiley-Interscience: New York, 1987, p 24) but this method is not experimentally useful in this case due to the low solubility of the substrates.

14. Tabushi, I; Kuroda, Y In Advances in Catalysis, Vol. 32, Elley, D. D.; Pines, H. Weisz, P. B. Ed, Academic Press: New York, 1983, p 422. 
15. (a) Fernandes, L. P.; Ehen, Z.; Moura, T. F.; Novak, C.; Sztatisz. J Therm.Anal Calorim. 2004, 78, 557. (b) Novak, C.; Fodor, M.; Pokol, G.; Izvekov, V.; Sztatisz, J.; Arias, M. J.; Gines, J. M. J. Therm. Anal. Calorim. 1998, 51, 1039.

16. Pinto, L. M. A.; deJesus, M. B.; dePaula, E.; Lino, A. C. S.; Alderete, J. B.; Duarte, H. A.; Takahata, Y. J Mol.Struc.Theochem 2004, 678, 63.

17. Kodaka, M. J. Phys Chem. 1991, 95, 2110.

18. Kodaka, M. J. Am. Chem. Soc. 1993, 115, 3702.

19. Steer, R. P. Rev. Chem. Intermediates 1981, 4, 1.

20. Fernandez, M. A.; de Rossi, R. H. J. Org. Chem. 2003, 68, 6887 and references cited therein.

21. The software included in Sigmaplot version 8.0 was used for the curve-fitting.

22. We thank Ferromet Argentina for the donation of this cyclodextrin.

23. Aimar, M. L.; Kreiker, J.; de Rossi, R. H. Tetrahedron Lett. 2002, 43, 1947. 